\title{
Web portal on environmental sciences "ATMOS"
}

\author{
E. P. Gordov ${ }^{1}$, V. N. Lykosov ${ }^{2}$, and A. Z. Fazliev ${ }^{3}$ \\ ${ }^{1}$ Siberian Center for Environmental Research and Training and Institute of Monitoring of Climatic and Ecological Systems \\ SB RAS, 10/3 Akademicheskii Ave., Tomsk, 634055 Russia \\ ${ }^{2}$ Institute for Numerical Mathematics RAS, 8 Gubkina Str., Moscow, 119991 Russia \\ ${ }^{3}$ Institute of Atmospheric Optics SB RAS, 1 Akademicheskii Ave.,Tomsk, 634055 Russia
}

Received: 15 September 2005 - Revised: 10 January 2006 - Accepted: 25 January 2006 - Published: 6 June 2006

\begin{abstract}
The developed under INTAS grant web portal ATMOS (http://atmos.iao.ru and http://atmos.scert.ru) makes available to the international research community, environmental managers, and the interested public, a bilingual information source for the domain of Atmospheric Physics and Chemistry, and the related application domain of air quality assessment and management.

It offers access to integrated thematic information, experimental data, analytical tools and models, case studies, and related information and educational resources compiled, structured, and edited by the partners into a coherent and consistent thematic information resource. While offering the usual components of a thematic site such as link collections, user group registration, discussion forum, news section etc., the site is distinguished by its scientific information services and tools: on-line models and analytical tools, and data collections and case studies together with tutorial material.
\end{abstract}

The portal is organized as a set of interrelated scientific sites, which addressed basic branches of Atmospheric Sciences and Climate Modeling as well as the applied domains of Air Quality Assessment and Management, Modeling, and Environmental Impact Assessment. Each scientific site is open for external access information-computational system realized by means of Internet technologies. The main basic science topics are devoted to Atmospheric Chemistry, Atmospheric Spectroscopy and Radiation, Atmospheric Aerosols, Atmospheric Dynamics and Atmospheric Models, including climate models.

The portal ATMOS reflects current tendency of Environmental Sciences transformation into exact (quantitative) sciences and is quite effective example of modern Information Technologies and Environmental Sciences integration. It makes the portal both an auxiliary instrument to support interdisciplinary projects of regional environment and extensive educational resource in this important domain.

Correspondence to: E. P. Gordov

(gordov@scert.ru)

\section{Introduction}

The Internet increasingly functions as the backbone of interdisciplinary collaborative research in area of environment, and becomes a tool for the efficient access to, and exchange of research data and tools. Among a set of project aimed at development of environment for cooperative work with Earth system science information resources and mathematical models most promising are described in http://www.enes. org, http://www.esmf.ucar.edu, http://www.earthsystemgrid. org. The central technical problem there is to give researchers opportunity to integrate mathematical models of weather or climate forming from compound for different subsystem behavior and save them from tedious tasks related with harmonization of input and output data of different models developed by different groups. At the same time models for each subsystem comprise a number of physical and chemical processes, which are studied by hundreds research groups. Thus there appears a problem of detailed comparative study of these models and multivariate construction of research integrative models, which is not solved on the current stage of development of cooperative modeling within Internet. Below an approach to this problem used at development of the web portal on Atmospheric Sciences ATMOS is presented.

The bilingual ATMOS web portal comprises information resources on physics and chemistry of atmosphere (http: //atmos.iao.ru) as well as those on air quality issues and two Siberian territorial objects, which are West Siberia and Lake Baikal (http://atmos.scert.ru). Design of an information resource implies development of different level models describing the chosen thematic area. In our case Siberia is an object of investigations and its properties under investigation are weather and climate. Their description is based on atmospheric dynamics, which requires knowledge of atmospheric radiation and subsequently of major chemical cycles in different atmospheric layers. To calculate radiation fluxes in atmosphere one has to deal with spectral properties

Published by Copernicus GmbH on behalf of the European Geosciences Union. 
of atmospheric gases and aerosols, whose concentrations are determined by photo-chemical transformations. Investigation of those properties is domain on a set of basic sciences including atmospheric spectroscopy, atmospheric chemistry, atmospheric radiation and atmospheric aerosols. The major concern in process of the portal design was to provide a qualified user with opportunity to get relevant information on all levels of relevant physical and chemical processes descriptions. Say, in the portal part dealing with atmospheric processes major part of calculation tasks are decomposed into elemental stages, which can be controlled by user. Below the two groups of the portal are described briefly. It should be noted that the thematic domains presented in the system cover the area of basic atmospheric science and it applications, in which either project partners or their collaborators group have professional expertise. The collaborators, mainly belonging to SB RAS research institutions, also formed a user group, whose requirements were taken into account in process of the system design and development.

\section{Thematic sites of atmospheric physics and chemistry group}

Each site of this group is based on databases or data sets inherent to its thematic domain. Computational models accessible in the portal after registration include the 3-D atmospheric circulation (climate) model of INM RAS (Alekseev, 1998), land cover-atmosphere interaction INM RAS model (Volodin, 1998), model of light scattering on spherical particles (Vasiliev, 1996, 1997), model describing short and long wave radiation in atmosphere (Barker, 2003), etc. The group comprises six sites, four of which are described below.

\subsection{Atmospheric spectroscopy (http://saga.atmos.iao.ru/)}

This information system is based on the Hitran (Rothman, 1998) and Geisa (Jacquinet-Husson, 1999) spectral data banks. Within it user can simulate spectral properties of an isolated molecule as well as of homogeneous or inhomogeneous molecular gas. Calculated data can be presented in table or graphical form. Graphical data presentation can be done by low end graphic, when only relevant plot is available to user, or by high resolution end graphic. In this case, user is provided with data massive and relevant web services allowing him different presentations, scales, sets of curves, etc. Fig. 1 shows the graphical presentation of $\mathrm{CO}_{2}$ molecule spectrum.

This information-computational system is provided with other services as well. Its information part contains in particular some text books on molecular spectroscopy (Sinitsa, 2003; Tonkov , 2000). More detail description of the site is given in (Bykov, 2004; Fazliev, 2005; Kozodoev, 2005).

\subsection{Atmospheric aerosol (http://aerosol.atmos.iao.ru/)}

Information part of this site comprises two editions of three volumes of M. V. Kabanov monograph "Optics of disperse media", L. S. Ivlev monograph "Physics of atmospheric aerosols systems" and materials of nine annual Workshops "Siberian Aerosols".

Computational component of the site includes a version of the aerosol calculator (Aerosol Measurement, Principle, 2001), which performs algebraic computations of aerosol physical characteristics, the Andreev-Ivlev model (Kozodoeva, Lavrentiev, 2005) for calculations of near - earth layer aerosols characteristics on horizontal paths and relevant extinction/absorption factors as well as for calculations of scattering matrix elements for radiation scattered on single or two layer particle and ensemble of particles.

\subsection{Atmospheric chemistry (http://atchem.atmos.iao.ru/)}

This information-computational system is aimed at organization of access to atmospheric chemical reactions database, derivation of kinetic equations for a chosen by user reaction set and qualitative analysis of the derived kinetic equations. Within it local chemical processes occurred at atmospheric conditions are analyzed in the following order:

1. Chemical reactions/cycles choice from the database (chemical system forming);

2. Kinetic equations derivation (closed or open systems);

3. Choice of atmospheric conditions for subsequent analysis (altitude, temperature, pressure, statistical model of atmosphere, albedo of surface, etc.);

4. Calculation of reactions coefficients;

5. Determination of the chemical system steady states and relevant time constants;

6. Determination of atmospheric compounds concentrations time behavior;

7. Determination of the chemical system phase portraits and analysis of scenario for its possible dynamical behavior.

The above steps are supported by a specially developed dialog system. This site is described in details in monograph (Gordov, 2002).

\subsection{Atmospheric radiation (http://atrad.atmos.iao.ru/)}

This site supports calculations of radiation fluxes in cloudless cloud atmosphere. Here accessible are the model (Barker et al., 2003), the Frolkis model (Frolkis, 1993) as well as a software support for atmospheric transmittance function calculations (Kozodoeva and Firsov, 2005). The information 


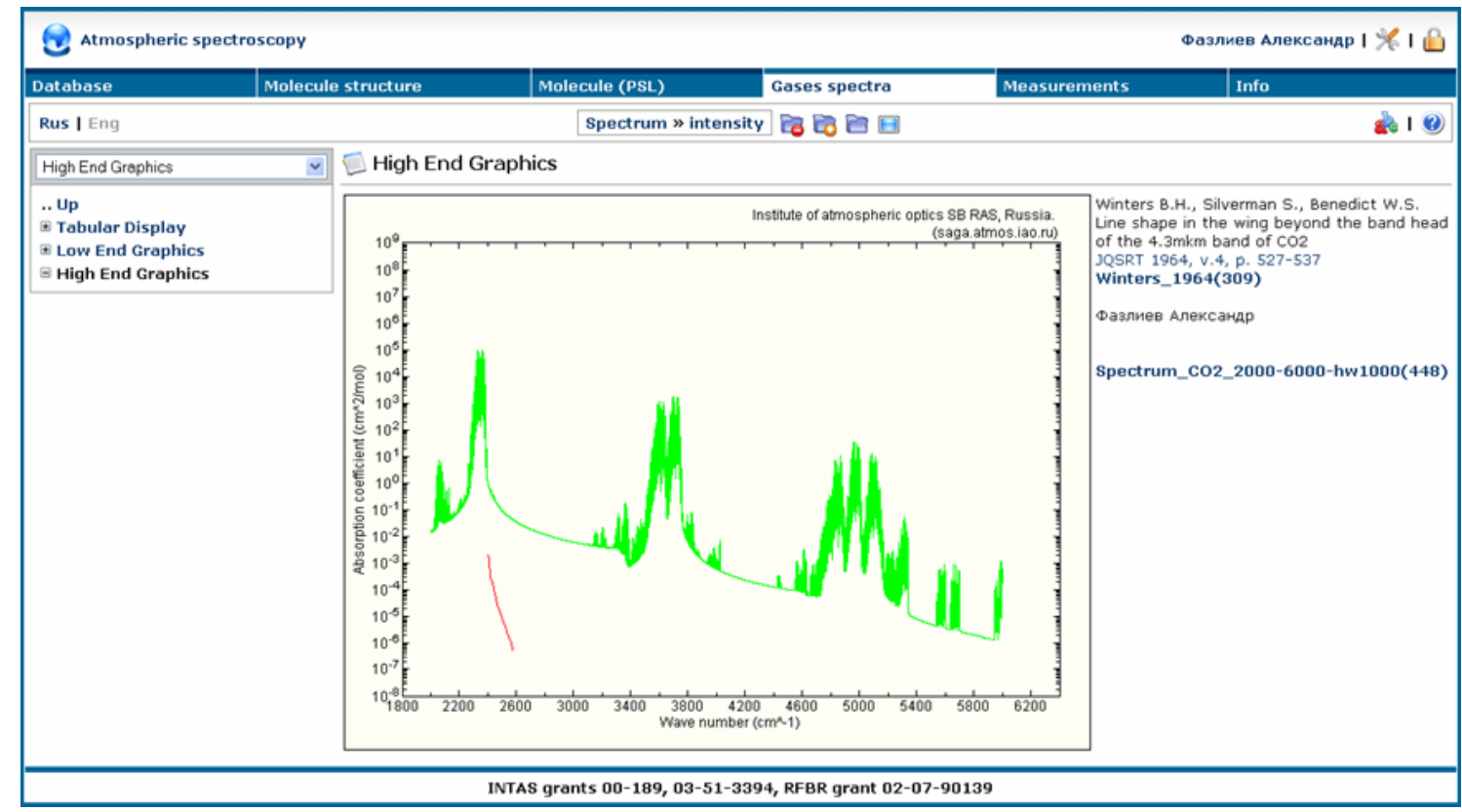

Fig. 1. High resolution end graphics example (absorption coefficient of $\mathrm{CO}_{2}$ in spectral range 1900-6000 $\mathrm{cm}^{-1}$ ).

part of the site contains data on two statistical models of atmosphere (Anderson, 1986; Zuev, 1986) and monograph by A. V. Vasiliev and I. N. Mel'nikova "Shortwave solar radiation in the Earth atmosphere: Calculations, measurements and interpretation". An example of a screenshot from the site is shown below.

\section{The second group of the sites}

Each site of this group is an information system devoted to relevant environmental issues, including atmospheric pollutions and environmental characteristics of two geographic objects of Siberia, namely Lake Baikal and West Siberia Plain.

\subsection{Air quality assessment and management (http://air.atmos.scert.ru/)}

Here an access to information resources on air quality monitoring and management and general description of Siberia environment state is given as well as to the AIR-EIA system, which was designed by a project partner to provide improved access to state-of-the-art mutli media information resources on Air Pollution aspects of Environmental Impact Assessment.

\subsection{Lake Baikal (http://baikal.atmos.scert.ru/)}

The site contains the first results of scientific assessment of the environmental and climatic situation in the Lake Baikal area. It is based on the book "Ecologically oriented land use planning in the Baikal region" by A. N. Antipov, V. M. Plusnin, O. I. Bashenova and others - Irkutsk: Published by the Institute of Geography SB RAS, 2002, 103 p. and gives an access to relevant descriptions, maps and photos.

\subsection{West Siberia (http://west-sib.atmos.scert.ru/)}

The site contains the first results of scientific assessment of the environmental and climatic situation in the region important for climatic variations under natural and anthropogenic pressure. Descriptions of regional climate, hydrology, vegetation and other environmental characteristics are given. It also includes a book summarizing recent findings on Great Vasyugan Bog state and dynamics.

\section{Development of software tools}

To support portal operation a special middleware was designed (Akhloystin, 2003). Based on it portal operates as an Internet accessible multi-user system oriented on applied problems solving. In it user can solve typical problems from the thematic domains, save intermediate of final results on the server side, compare results with stored in the system experimental or computational data (this functionality is supported for molecular spectroscopy only), etc. To submit data required in computational tasks or to choose those from the prepared list specially designed on the base of recommendations on HTML interfaces are used. Figure 3 presents structure of the portal and middleware.

An apparatus part comprises three components, which are database server, applications server and computational 


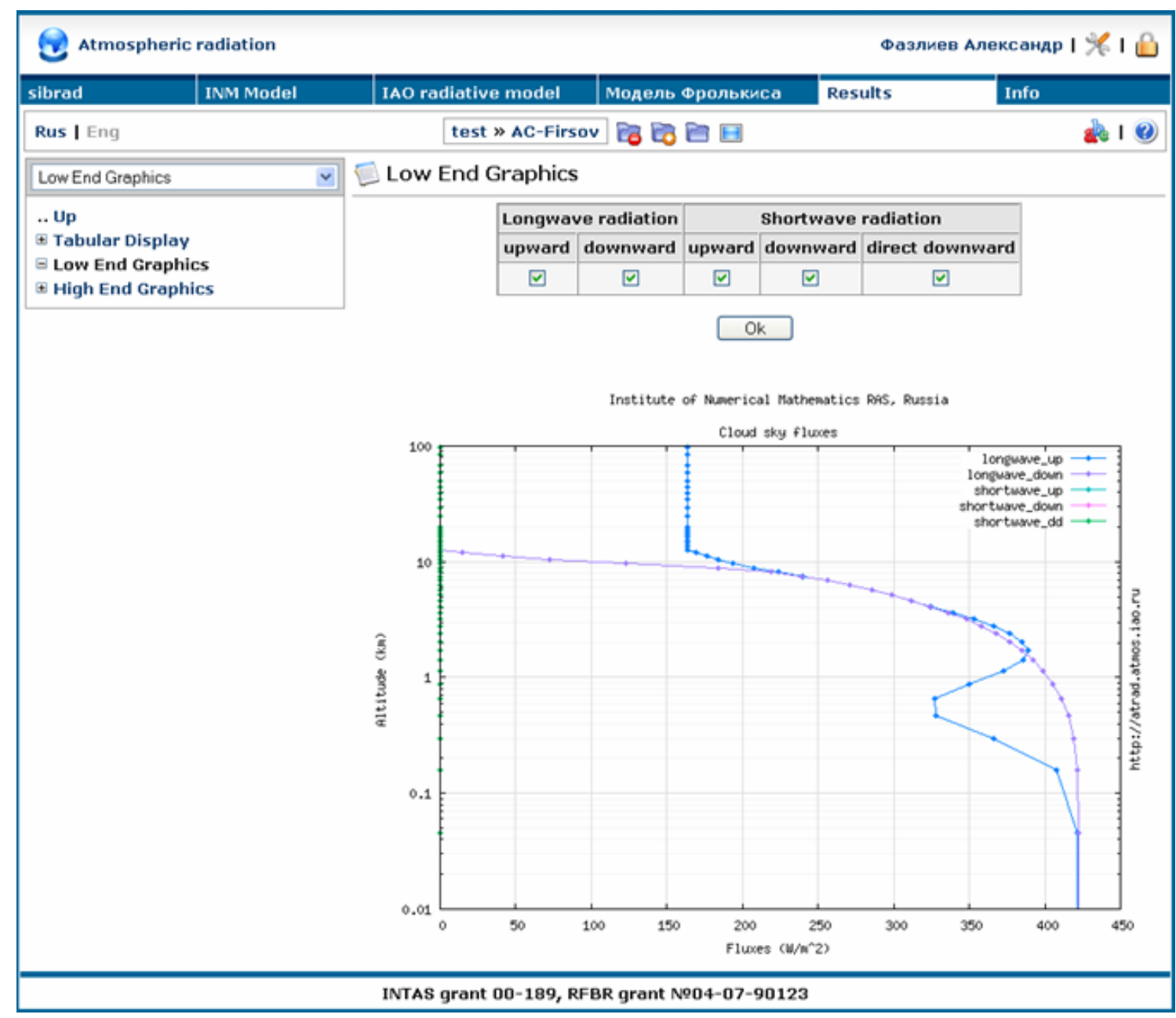

Fig. 2. Results of fluxes calculation in the framework of the zonal model of the atmosphere.

cluster oriented to atmospheric chemistry and climate problems solving. The middleware consists of a set of services and a transaction processing monitor, which performs function of a dispatcher of each user request and of some services. Part of the services is shown on Fig. 3. The dialogue system forms menu on the base of applied logic formed for each site. The user's data control system secure integrity of user's data in process of usage of the relevant site calculation part. The linguistic service is providing multi-language information presentation on site and in the dialogue system. Since till now there is no international standards on relevant middleware (see, for example, Network Working Group, Request for Comments: 2768) technological choices were based of W3C recommendations. In particular, Apache web server was used as well as PHP script language and MySQL DBMS. It should be noted that a "make" approach was used since at the start of the project in 2000 there was no software available, which allowed one to develop Internet accessible systems aggregating computational applications with a dynamically formed dialog system and control of integrity of user's data saved at the server side. Typical software adjusted to these tasks is not available yet. It should be also added that to make the information-computational system open via Internet to professional community we used a multilevel clientserver architecture. Relevant software significantly differs from those adjusted for LAN. Here the key elements are a web-server, supporting its operation middleware and standards for data and metadata descriptions. While the standards are elaborated by $\mathrm{W} 3 \mathrm{C}$ and web-servers are suggested by companies developing software the middleware is still the domain in which neither standards nor companies developing software are presented. This area is actively developed only nowadays, see, for example, works on Internet-2, supported by NSF (USA) (http://middleware.internet2.edu).

\section{Conclusions}

The portal ATMOS reflects current tendency of Environmental Sciences transformation into exact (quantitative) sciences 


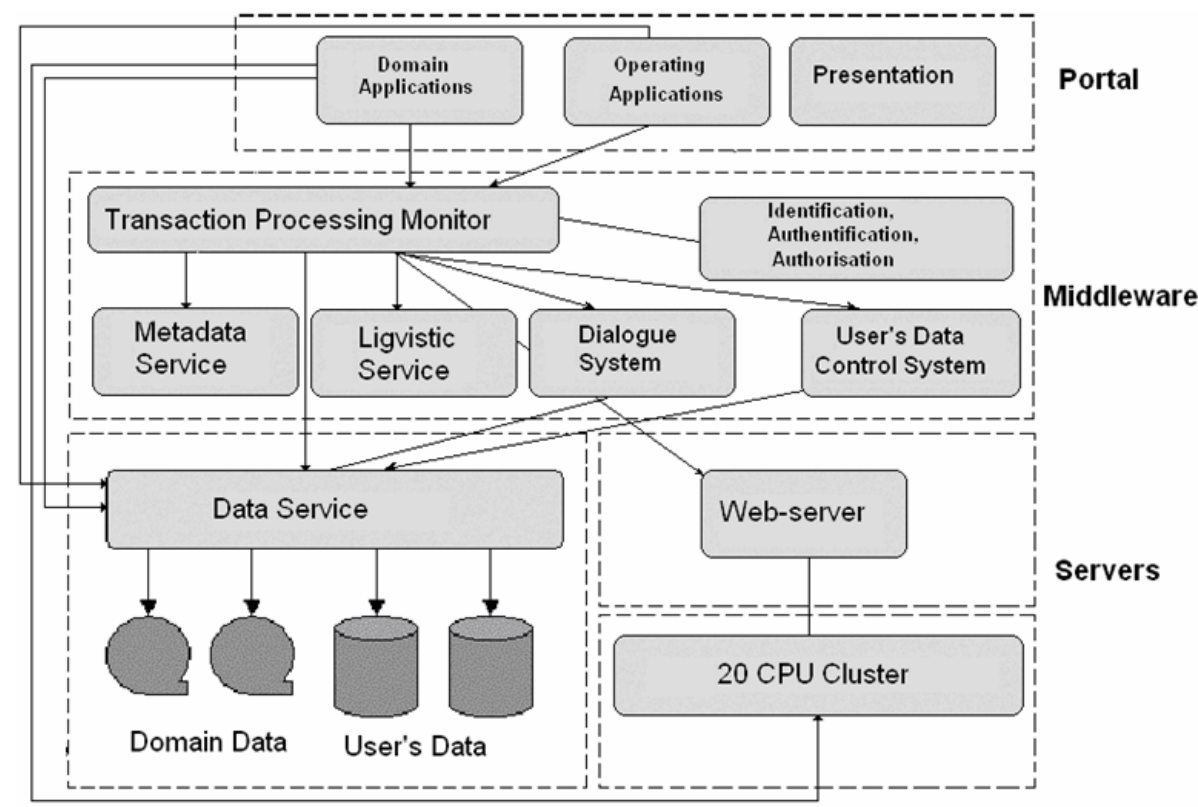

Fig. 3. The portal and the middleware structure.

and is quite effective example of modern Information Technologies and Environmental Sciences integration. It makes the portal both an auxiliary instrument to support interdisciplinary projects on Siberia regional environment and extensive educational resource providing an access to number of textbooks and monographs in the targeted domains of atmospheric sciences and their applications. It should be added that middleware developed to construct and support the portal sites allows one to design a management system for such projects as a part of relevant information computational site. In virtue of limited resources, currently it can be achieved on project to project basis only. First steps in this directed were done within the interdisciplinary project of SB RAS No 138 "Siberian Geosphere-Biosphere Program", see for example the project site http://sgbp.scert.ru/en/.

Given above brief description of the ATMOS portal structure and gathered information resources indicates possible ways of its development. The first one is in integration into the portal new sites oriented on description of specific processes of land-atmosphere interactions. Here sites devoted to atmosphere - vegetation and atmosphere - hydrologic system (bogs, rivers, and lakes) are among the first candidates for development and integration. Development of a site devoted to atmospheric boundary layer is in process at now with a support from RFBR. The second way is in compilation and classification of results of measurements or computations of physical characteristics of objects included into consideration. To this end additional technical tools should be developed. In particular it includes a middleware for distributed information-computational systems, tools to work with knowledge bases formed on the base of relevant mea- surements and/or calculations, provided with machine-read metadata. Development of a distributed system on molecular spectroscopy supported by RFBR grant is a first step in this direction.

Acknowledgements. Basic part of this work was done with INTAS grant 00189 support. Its continuation is partially supported by SB RAS Interdisciplinary Project No. 138 and RFBR grants 04-07-90219, 05-05-98010 and 05-07-90196.

Edited by: E. Cutrim, M. Ramamurthy, S. Nativi, and L. Miller Reviewed by: anonymous referees

\section{References}

Baron, P. A. and Willeke, K. (Eds.): Aerosol Measurement, Principle, Techniques, and Applications, 2 ed., J. Wiley, N.Y. 1132p., 2001.

Akhlyostin, A. Yu. and Fazliev, A. Z.: Software for presentation of scientific information in the framework of a WEB portal, Proc. SPIE. v.5396, 111-118, 2003.

Alekseev, V. A., Volodin, E. M., Galin, V. Ya., Dymnikov, V. P., and Lykosov, V. N.: Modern climate modelling on the base of INM RAS atmospheric model, Moscow, VINITI, 120 p., 1998.

Anderson, G., Clough, S., Kneizys, F., Chetwynd, J., and Shettle, E.: AFGL Atmospheric Constituent Profiles (0-120 km), Air Force Geophysics Laboratory, AFGL-TR-86-0110, Environmental Research Paper No. 954, 1986.

Barker, H. W., Stepfens, G. L., Partain, P. T., Galin, V. Ya., et al.: Assessing 1D Atmospheric Solar Radiative Transfer Models: Interpretation and Handling of Unresolved Clouds, J. Climate, v.16, 16, 2676-2699, 2003.

Bykov, A. D., Voronin, B. A., Kozodoev, A. V., Lavrent'ev, N. A., Rodimova, O. B., and Fazliev, A. Z.: Information system for 
molecular spectroscopy. 1. Structure of information resources, Atmos. Ocean Opt., 17, 11, 816-820, 2004.

Fazliev, A. Z.: Description of the informational resources for molecular spectroscopy on the base of XML platform, Comput. Technologies, v.10, part1, 39-46 (in Russian), 2005.

Frolkis, V. A. and Rozanov, E. V.: Radiation Code for Climate and General Circulation Models, in : IRS'92 Current problems in Atmospheric Radiation, edited by: Keevallik, S., A.DEEPAK Publishing, Hampton, VA 23666, USA, 176-179, 1993.

Gordov, E. P., Rodimova, O. B., and Fazliev, A. Z.: Atmospheric and optical processes: unsophisticated nonlinear processes, Tomsk, IAO SB RAS Publishing, 252pp., 2002.

Jacquinet-Husson, N., Arie E., Ballard, J., et al.: The 1997 spectroscopic GEISA databank, J. Quant. Spectrosc. Radiat. Transfer, 62, 205-254, 1999.

Kozodoev, A. V. and Fazliev, A. Z.: Information system for molecular spectroscopy. 2. Operations over the set of the spectral line parameters, Atmos. Ocean Opt., 18, 9, 760-764 (in Russian), 2005.

Kozodoeva, E. M., Lavrentiev, N. A., and Fazliev, A. Z.: The informational resources for investigations of atmospheric aerosols, Comput. Technol., 10, part 2, 20-31 (in Russian), 2005.
Kozodoeva, E. M. and Firsov, K. M.: Data-processing system "Atmospheric radiation", in: Proc. of 10 Baikal Conf. "Math. and Inform. Technologies", 51-56, 2005.

Rothman, L. S., Rinsland, C. P., Goldman, A., et al.: The HITRAN molecular spectroscopic database and HAWKS (HITRAN Atmospheric WorkStation): 1996 edition, J. Quant. Spectrosc. Radiat. Transfer, 60(5), 665-710, 1998.

Volodin, E. M. and Lykossov, V. N.: Parameterization of heat and water exchange processes in soil-vegetation system for general atmospheric circulation modeling, Izvestia RAS, Atmos. Ocean Phys., 34, 453-465, 1998.

Vasiliev, A. V.: Universal algorithm for calculation of the optical characteristics for homogeneous spherical aerosol particles, S. Petersburg Univ. Vestnik, Ser. 4: Physics, chemistry. I. Single Particles, 4, 25, 3-11, 1996, II. Particles ensembles, 1, 4, 14-24, 1997.

Zuev, V. E. and Komarov, V. S.: Statistical models of the temperature and gaseous components of the atmosphere, Gidrometeoizdat, Leningrad, 264pp. (in Russian), 1986. 